\title{
Desinformación en contextos de polarización social: el paro nacional en Colombia del $21 \mathrm{~N}^{*}$
}

\author{
Carlos Rodríguez Pérez ${ }^{* *}$ \\ Laura Sofía Ortiz Calderón*** \\ Juan Pablo Esquivel Coronado*** \\ Recibido: 2020-07-02 • Enviado a pares: 2020-07-20 \\ Aprobado por pares: 2020-08-05 - Aceptado: 2020-08-22 \\ https://doi.org/10.22395/angr.v19n38a7
}

\begin{abstract}
Resumen
La desinformación se ha convertido en un fenómeno mundial que incide en la opinión pública. El objetivo de este artículo es analizar los contenidos evaluados como desinformación por tres medios de verificación durante el paro nacional del 21 de noviembre del 2019. Específicamente, se pretende conocer cómo la desinformación afecta negativamente los bienes intangibles (legitimidad, reputación y confianza) de actores sociales, políticos e instituciones. Metodológicamente, se realizó un análisis de contenido cuantitativo y etnográfico para analizar los datos e identificar argumentos y patrones de relación de la desinformación con su afectación en la intangibilidad de estos clústeres de actores. Los resultados obtenidos destacan que la desinformación propagada vinculó la violencia y los actos punibles tanto a los actores sociales como a la fuerza pública, especialmente al Esmad y a la policía, con el fin de deslegitimar y desacreditar las razones de la protesta o bien su labor de garantizar el orden público y la seguridad. Respecto a la desinformación vinculada con los actores políticos se observa que el líder de la izquierda fue el más afectado por contenidos que polarizaban y proclamaban posiciones extremas cercanas a la subversión. Por último, se discuten las implicaciones de la desinformación en la ciudadanía y cómo incide sobre la legitimidad, reputación y confianza. Además, se evidencia que la desinformación imita la estética de medios de comunicación para dotarse de una falsa legitimidad y credibilidad ante los ojos de la audiencia.
\end{abstract}

Palabras clave: periodismo de verificación; desinformación; flujo de noticias; medios sociales; medios de comunicación; política; problema social; Colombia.

Este artículo es resultado del proyecto de investigación Knocking down fakes news: Analysing Fact-checking journalism processes and effects (Desmintiendo las noticias falsas: Un análisis de los procesos de comprobación de hechos en el periodismo y sus efectos), financiado por la Universidad de Ibagué, Tolima, Colombia.

* Doctorando en Ciencias de la Información, Universidad Complutense de Madrid, Madrid, España; magíster en Comunicación Política e Institucional, Instituto Universitario de Investigación Ortega y Gasset, Madrid, España; magíster en Marketing, Consultoría y Comunicación Política, Universidad de Santiago de Compostela, Santiago de Compostela, España. Profesor asociado, Universidad de Ibagué, Ibagué, Colombia.Correo electrónico: carlos.rodriguez@unibague.edu.co. Orcid: https://orcid.org/0000-0002-4830-5554

... Estudiante de Ciencias Políticas de la Universidad de Ibagué, Ibagué, Colombia. Correo electrónico: 5220181009@estudiantesunibague. edu.co. Orcid: https://orcid.org/0000-0001-9529-3536

.... Estudiante de Ciencias Políticas de la Universidad de Ibagué, Ibagué, Colombia. Correo electrónico: 5220181003@estudiantesunibague. edu.co. Orcid: https://orcid.org/0000-0001-8979-8685 


\title{
Disinformation in Contexts of Social Polarization: Colombia's National Strike (November 21 1 st, 2019)
}

\begin{abstract}
Disinformation emerges as a worldwide phenomenon that affects public opinion. The article's purpose is to analyze the contents evaluated as disinformation by three fact-checking media during Colombia's national strike (November 21 st, 2019). Specifically, the objective is to understand how disinformation negatively affects the intangible assets (legitimacy, reputation, and trust) of social $\varepsilon$ political actors, and institutions. Methodologically, we carried out both quantitative and ethnographic content analysis to analyze data and, identify the prominent arguments and relationships. Through this, we linked the disinformation and the costs of the intangible assets associated with these actors and institutions. The results highlight that the disinformation contents' key drivers were the violence and punishable acts that affected both social actors and the Public Force, particularly the Esmad and the police. These contents delegitimized and discredited both the reasons for the protest and the function of guaranteeing public order and security. Regarding the disinformation linked to political actors, the leader of the left-side was the most affected due to inaccurate content that polarized and proclaimed extreme positions close to subversion. Finally, we discuss the implications of disinformation and how it affects legitimacy, reputation, and trust. Moreover, disinformation imitates media outlet aesthetics as a necessity of a kind of legitimacy and credibility set of news practice in the eye of the beholder. Keywords: fact-checking journalism; disinformation; news flow; social media; mass media; politics; social problems; Colombia.
\end{abstract}




\section{Introducción}

El pasado 21 de noviembre del 2019 tuvo lugar en Colombia un paro nacional convocado por diversos sectores sociales como protesta y manifestación de descontento por la ruta política del Gobierno. Este entorno de polarización social y política propicia la divulgación de numerosa información, la cual, a menudo, se torna en desinformación al circular con datos falsos, contextos equívocos o con imágenes o videos manipulados. Medios sociales como las redes sociales (Facebook o Twitter) o aplicaciones privadas de mensajería instantánea como WhatsApp han transformado las vías de acceso y consumo de información, hasta el punto de que dichas plataformas han realizado un baipás a los medios de comunicación como filtro informativo en los sistemas democráticos (Strömbäck, 2008).

Este artículo, por tanto, investiga el fenómeno de la desinformación (Allcott y Gentzkow, 2017; Lewandowsky, Ecker y Cook, 2017; Vargo Guo y Amazeen, 2018; Wardle y Derakhshan, 2017; Zimmermann y Kohring, 2020) en un clima social polarizado. Para ello, recurrimos al periodismo de verificación (Cheruiyot y Ferrer-Conill, 2018; Graves, 2017; Mena, 2019) para identificar esta contaminación informativa. A través de los contenidos evaluados por los periodistas de verificación como desinformación se pretende hallar qué efecto genera la desinformación sobre intangibles como la legitimidad, reputación y confianza de actores políticos, sociales e institucionales. La desinformación amenaza los sistemas democráticos (Tenove, 2020). Los problemas de legitimidad y confianza motivan que los ciudadanos escépticos consuman información por medios y canales alternativos (Bennett y Livingston, 2018) donde suele propagarse la desinformación.

Por ello, se propone responder las siguientes preguntas de investigación, así como se plantean las hipótesis:

Pregunta 1: ¿Cómo afecta la desinformación en los actores políticos, sociales e institucionales en un sistema democrático polarizado?

Hipótesis 1: La desinformación influye de forma negativa en bienes intangibles de actores políticos, actores sociales e instituciones públicas.

Pregunta 2: ¿Qué argumentos de desinformación se compartieron y qué efectos generan en la legitimidad, reputación y confianza de estos actores?

Hipótesis 2: La desinformación se convierte en un riesgo para la legitimidad, reputación y confianza social de estos actores.

Por valor intangible, partimos de la explicación de Canel y Luoma-aho (2017), quienes sostienen que 
[e]s la cohesión social con que un país reacciona ante un atentado terrorista, el sentido de seguridad con que los ciudadanos circulan por las calles o la solidaridad con que la sociedad civil atiende el problema del hambre. Son estas realidades intangibles, en cuyo valor (incremento o descenso) la Administración pública está directamente implicada; y cuyo valor determinará también la marcha y el progreso de las sociedades. (p. 37)

A partir de estas hipótesis presentamos los objetivos de investigación:

Objetivo 1: Analizar los argumentos de los contenidos desinformantes en función de los actores políticos, sociales o instituciones públicas.

Objetivo 2: Conocer las implicaciones que pretenden generar dichos contenidos evaluados como inexactos sobre los bienes intangibles de actores e instituciones a partir de los conceptos intencionalidad y daño de la desinformación (Wardle y Derakhshan, 2017).

Para cumplir con este propósito se desarrolla, en primer lugar, el contexto político y social que permita comprender el estado de la opinión pública polarizada de Colombia en el momento en el que tuvo lugar el paro nacional. Seguidamente, se aborda el marco teórico relacionado con el estudio y los efectos de la desinformación en la sociedad, así como el papel del periodismo de verificación como emergente práctica periodística para combatir la información falsa. Posteriormente, se detalla la metodología implementada, se presenta el análisis de los resultados, cuyas implicaciones y alcances se discuten, así como las conclusiones que se derivan.

\section{El contexto político y social}

"El pulso de la democracia en la región se mantiene débil" (Zechmeister y Lupu, 2019, p. 1). Así comienza el informe 36 del Barómetro de las Américas 2018/19, el cual incluye encuestas representativas a nivel nacional realizadas en los principales países del continente americano.

Latinoamérica, en 2019, enfrentó grandes cambios políticos y económicos. Distintos presidentes como Andrés Manuel López Obrador (México), Iván Duque (Colombia) y Jair Bolsonaro (Brasil) cumplieron un año de mandato, y Sebastián Piñera (Chile) arrancó su segundo año. Así mismo, se dieron elecciones presidenciales en El Salvador, Panamá, Guatemala, Uruguay, Argentina y Bolivia, además de la creciente crisis institucional en Venezuela. Este contexto político estuvo avivado por un clima polarizado que dio paso a las masivas protestas que se vivieron en países como Venezuela, Argentina, Bolivia, Chile, Ecuador, Haití, Honduras, Nicaragua, Paraguay, Perú y Colombia. 
Todo ello se entiende desde distintos datos contextuales aportados por el Barómetro de las Américas (Zechmeister y Lupu, 2019). El apoyo a la democracia acentúa una tendencia negativa prolongada desde el año 2006. Actualmente solo el 57,7 \% de los encuestados apoya el sistema democrático. Relacionado con lo anterior, la legitimidad política, es decir, la percepción de los ciudadanos de que las instituciones y los procesos básicos de su país son dignos de respeto y confianza, se mantiene en cifras bajas en la mayoría de los países latinoamericanos. De los dieciocho países encuestados, ninguno alcanzó cifras superiores al 60 \% y diez de ellos no llegaron al 50 \%. Estas tendencias coinciden con los datos de la Corporación Latinobarómetro (2018) que también dibuja una tendencia negativa desde el 2010 relacionada con el apoyo a la democracia. En 2018 la situaron en el 48 \% y únicamente el $24 \%$ se mostraba satisfecho. La aprobación media de los gobiernos latinoamericanos se situó en el $32 \%$.

Estos déficits de legitimidad social de los Gobiernos y la débil consolidación de las democracias en América Latina nos permiten recuperar la obra de Huntington citada por García (2012) y el ciclo pendular relacionado con la problemática de la ingobernabilidad. En este sentido, afirma Huntington (1994):

Este catalogó la aparición de las democracias como un acontecimiento cíclico. Al parecer, luego de analizar la evidencia empírica histórica, se puede observar que esta forma de gobierno presenta un comportamiento pendular. A un tiempo de auge de regímenes autoritarios en el mundo parece sucederle uno de transición hacia regímenes democráticos que, luego de algún tiempo y a raíz de ciertos factores, da paso a la reaparición de los primeros. (p. 17)

A partir de esta perspectiva macro del contexto latinoamericano, nos centramos ahora en el contexto social y político colombiano, el cual se ha visto afectado por la polarización política (Duque-Daza, 2020). Históricamente, esto derivó en grandes conflictos como la Patria Boba, la época de la violencia o el conflicto armado interno (Yaffe, 2011) por mencionar solo algunos ejemplos. Desde el 2016, con la celebración del plebiscito por la paz, Colombia vive un proceso de polarización. Las elecciones generales del 2018, ganadas por Iván Duque, marcaron dos claras tendencias ideológicas entre la izquierda y la derecha. Desde su toma de posesión, el 7 de agosto del 2018, el actual presidente Iván Duque, apadrinado por el expresidente y senador Álvaro Uribe, sufre un importante déficit de popularidad. La encuesta de Invamer Gallup (2019) tasó en un 70 \% la desaprobación del presidente, el dato más elevado desde que inició su andadura en el Gobierno, dando continuidad a una tendencia alcista durante todo el 2019. Como dato complementario, el Barómetro de las Américas (Zechmeister y Lupu, 2019) cifró la legitimidad política colombiana en el $50,7 \%$ (figura 1). 


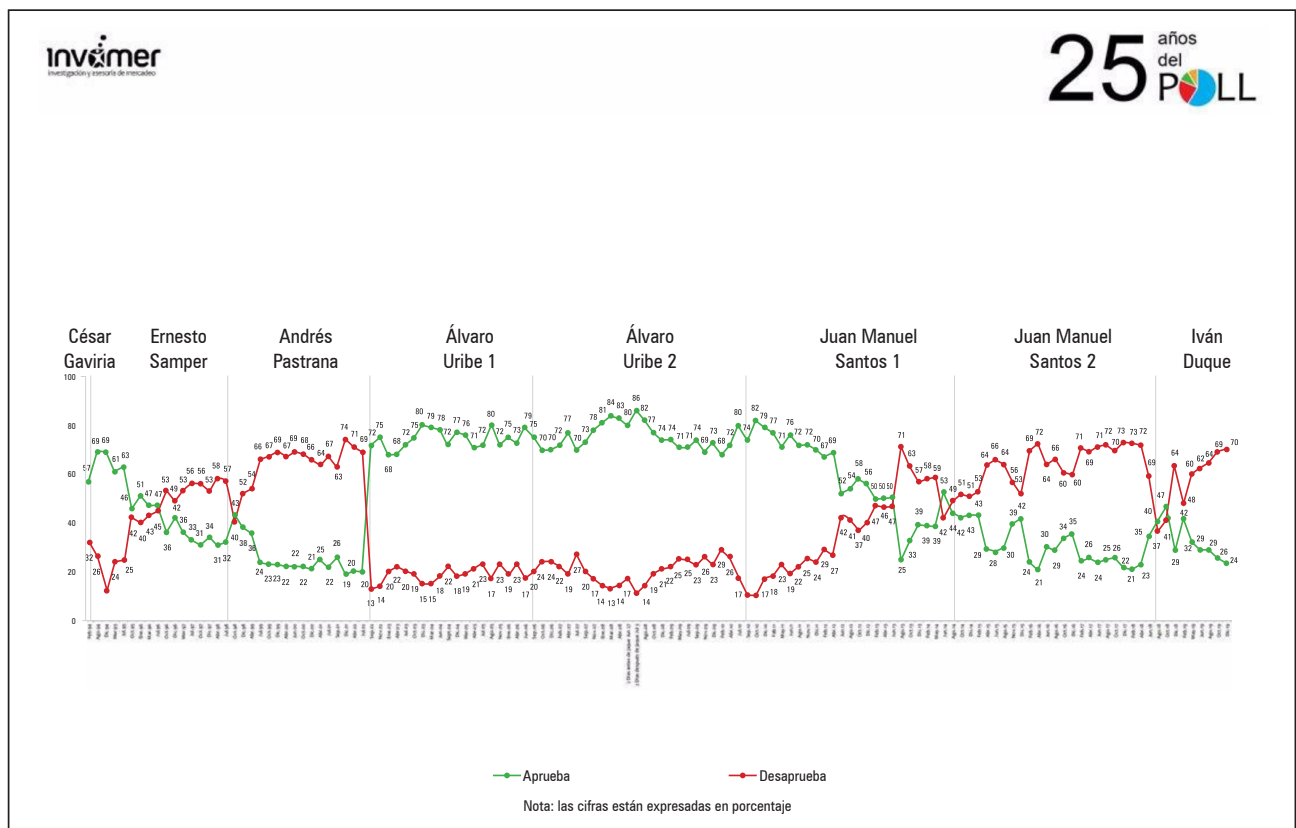

Figura 1. Aprobación del desempeño del presidente de la República de Colombia.

Fuente: Invamer Gallup (2019).

Por otro lado, la Encuesta de cultura política hecha por el Departamento Administrativo Nacional de Estadística [DANE] (2019) reproduce un contexto político en que se perciben importantes falencias en términos de confianza en el sistema democrático, en la confianza en las principales instituciones del país y la preocupación por la corrupción. Concretamente, el 47,1 \% de los encuestados señala sentirse muy insatisfecho con el funcionamiento de la democracia, en contraposición con el 16,4 \% que afirma sentirse muy satisfecho.

En relación con la confianza en las instituciones públicas, el estudio aporta datos críticos para todas ellas. El 37 \% de los encuestados manifiesta confiar mucho en las fuerzas militares. En segundo lugar, aparece la Registraduría Nacional del Estado Civil (30,7 \%), seguido por la Defensoría del Pueblo (29,2 \%), la Policía $(27,6$ \%) y la Presidencia de la República (27,6 \%), las Alcaldías (24,4 \%), Fiscalía General de la Nación (23,6\%), Gobernación (22,7 \%), Concejos Municipales (20,2%), Procuraduría General de la Nación (19,2\%), Contraloría (18,2\%), Congreso de la República (16,3\%), jueces y magistrados (16,1 \%), las asambleas departamentales (15,6\%) y los partidos políticos (12,2\%).

Respecto de la percepción de corrupción, el 64 \% considera corrupto o muy corrupto al Gobierno nacional, cifra que se eleva hasta el 68,8 \% si nos referimos al Congreso de la República. En el caso de la rama judicial este valor alcanza el 59,1 \%. 
Como complemento, la Corporación Latinobarómetro (2018) estableció que el apoyo a la democracia colombiana se sitúa en el $54 \%$, el 50 \% consideró que la democracia tiene grandes problemas y solo el $25 \%$ estaba satisfecho con el sistema. En términos de progreso de país, solo el 27 \% de los colombianos consideró que el país se encuentra en dicha dirección. Respecto de la gestión gubernamental, el $80 \%$ de los colombianos percibía que se gobierna para los grupos poderosos en su propio beneficio frente al $16 \%$ que consideró que se gobierna para todo el pueblo. Este clima negativo también se traslada a las instituciones y a los poderes del Estado: la confianza en el poder judicial era del $23 \%$; la confianza en el Parlamento, del $20 \%$; la confianza en los partidos, del $16 \%$; la confianza en el tribunal electoral, del $48 \%$; y la confianza en el Gobierno, del $22 \%$.

Adicionalmente, otros dos datos inciden en el clima social: el $20 \%$ de los colombianos consideró la corrupción como el principal problema del país y el 51 \% afirmó que sus ingresos no les alcanzan o tienen dificultades para satisfacer sus necesidades. En este sentido, un estudio de la Organización para la Cooperación y el Desarrollo Económico [OCDE] (2018) fijó que en Colombia se necesitan once generaciones para que una persona nacida en clase baja llegue a situarse en la clase media.

A partir de esta radiografía con datos del clima sociopolítico colombiano y la influencia del contexto, alentado por las protestas sociales en países vecinos, se comprende cómo en Colombia se desencadenó un paro (huelga) nacional el pasado 21 de noviembre del 2019 convocado por los sindicatos y asociaciones de estudiantes. El objetivo fue manifestar el rechazo al Gobierno de Iván Duque, la repulsa por los asesinatos de líderes sociales, los problemas de financiación de la educación, la preocupación medioambiental, la consolidación del proceso de paz y el desacuerdo con el Proyecto de Ley 212 que proponía contratos por horas para los jóvenes.

En una entrevista en el periódico nacional El Tiempo, el historiador Jorge Orlando Melo afirmó que "en Colombia, el descontento urbano no ha tenido representantes políticos importantes. Me parece que este movimiento actual expresa esa protesta difusa de sectores que nunca han podido participar políticamente porque nadie los ha representado" (Ortiz, 2019). Este rasgo tuvo su reverberación en la polarización del lenguaje. Tal y como recogen medios como la BBC (2019) o Revista Semana (2019) se calificó a la oposición de "castrochavismo", "petrismo" o "foro de Sao Pablo", en alusión a un grupo comunista internacional que envía manifestantes a distintos países para que logren el objetivo de instaurar el comunismo en América Latina. De esta manera, cumplieron con la noción del enemigo externo de Carl Schmitt (2014). En este sentido, el juego político colombiano inició una guerra mediática polarizada entre un "ellos" y un "nosotros". 
Esta división social propicia el auge de información falsa y manipulada. La Organización de los Estados Americanos [OEA] emitió una declaración en el año 2017 en la que muestra su preocupación por la incidencia de las noticias falsas, la propaganda y la información no objetiva "para confundir a la población y para injerir en el derecho del público a saber y en el derecho de las personas a buscar y recibir, y también transmitir, información e ideas de toda índole" (OEA, 2017). Los datos revelados por el informe Latin American Communication Monitor 2018-2019 (citado en Moreno et al., 2019) muestran que el 65 \% de los ciudadanos encuestados de América Latina ha prestado atención al tema de las noticias falsas, y Colombia es uno de los países donde más impacto tienen estas informaciones falsas. El fenómeno de la desinformación y las noticias falsas en particular perturban a múltiples esferas sociales. Concretamente, Colombia ocupa el segundo lugar entre los principales países latinoamericanos donde la incidencia de la desinformación en las organizaciones es mayor y sus consecuencias notables: una erosión hacia la confianza. No obstante, en términos generales, los más afectados por las noticias falsas son las personas (57,9\%), seguidas por las organizaciones (36,6\%) y los productos o servicios (35,9\%). En las elecciones presidenciales y legislativas del 2018, Hernández-Cadena et al. (2018), en una publicación de la Misión de Observación Electoral (MOE), hallaron una mutabilidad de los formatos de las noticias falsas para propagarse en varias redes sociales con implicaciones para el periodo electoral:

Las noticias falsas son un fenómeno que marcó la carrera electoral del 2018 en Colombia pues la credibilidad que se le dio a muchas de estas ocasionó no sólo un impacto en los votantes, sino también en los medios de comunicación, los cuales tuvieron que adaptar sus formatos para contrarrestar el efecto que tuvieron muchas de estas noticias. (p. 27)

Llegados a este punto, es necesario mencionar la reacción del periodismo a través de las crecientes iniciativas de periodismo de verificación que, a nivel mundial, combaten la desinformación. En el entorno en línea, los medios de comunicación colombianos cuentan con comunidades de seguidores. Pero estas son distintas de aquellas comunidades que viralizan la desinformación, por lo que no logran impactar en ellas. Por tanto, son pocos los usuarios que una vez expuestos a la mentira reciben la corrección (Hernández-Cadena et al., 2018). No obstante, en Colombia la confianza en los medios de comunicación es del 43 \% (Corporación Latinobarómetro, 2018), una cifra que el Barómetro de las Américas (Hagan, 2019) reduce hasta el 35,8 \%.

\section{El fenómeno de la desinformación}

El incremento en la propagación de la desinformación es un hecho innegable (Vargo, Guo y Amazeen, 2018). Apegado a la desintermediación, la conectividad 
y la proliferación de medios sociales, diversos estudios revelan la preocupación ciudadana sobre la exactitud de la información que reciben y cómo esto influye en el funcionamiento democrático (European Commission, 2018; Lewandowsky, Ecker y Cook, 2017; Newman et al., 2019).

La desinformación es un concepto poliédrico cuya cara más visible la protagonizan las noticias falsas. Para abarcar su definición, Tandoc, Lim, Ling (2018) destacan el parecido estético con las noticias reales, las similitudes de las páginas webs que las difunden con las páginas confiables, la redacción y los elementos gráficos que integran con la finalidad de disfrazar la intencionalidad de confundir en una espuria autenticidad, legitimidad y credibilidad ante los ojos de la audiencia (Baym, 2005). Es un disfraz de un producto mediático, eso sí, fraudulento.

Por su parte, Allcott y Gentzkow (2017) definen las noticias falsas como los artículos noticiosos que, de forma intencionada y comprobada, se demuestran falsos y llegan a confundir a los lectores. Por su parte, Rodríguez-Pérez (2019) aboga por no mezclar el contenido de falsedad con el género troncal del periodismo, como lo es la noticia, debido al oxímoron evidente en el término. No obstante, en la academia, el debate sobre la conceptualización de la desinformación, las noticias falsas o los desórdenes informativos no cesa. En este sentido, autores como Weeks y Gil de Zúñiga (2019) piden redoblar los esfuerzos en estudiar el impacto de la desinformación en las audiencias, los porqués y los efectos vinculados a nivel individual y sociopolítico.

Como reveló un estudio de Vargo, Guo y Amazeen (2018), las noticias falsas y los medios sociales partidistas aparecen fuertemente vinculados por dos motivos. En primera instancia, responden a las agendas de estos medios partisanos dado que estos actúan como predictores de la agenda de las noticias falsas. En segundo lugar, las noticias falsas tienen autonomía y capacidad para condicionar la agenda de los medios en temas clave como las relaciones internacionales, la economía o la religión. También se ha hallado evidencia de que la menor confianza hacia los medios y hacia la política hace más probable que uno confíe en la desinformación en línea (Zimmermann y Kohring, 2020). Esto es importante dado que sabemos que los intereses ideológicos, políticos y económicos están detrás de la creación y difusión de la desinformación (Allcott y Gentzkow, 2017) la cual se operacionaliza, con frecuencia, desde múltiples formatos multimedia que se viralizan.

En el establecimiento por acotar qué es desinformación se observan criterios que incorporan tanto los contenidos generados con fines de entretenimiento con aquellos que únicamente tienen la intención de engañar. De esta forma, Tandoc, Lim y Ling (2018) identifican seis categorías (sátira informativa, parodia informa- 
tiva, información fabricada, información manipulada, publicidad y propaganda). Por otro lado, Molina et al. (2019) enumeran siete categorías taxonómicas (información falsa, contenido polarizado, sátira, errores periodísticos, comentarios, información persuasiva y periodismo ciudadano). Además, Molina et al. (2019) reflexionan en torno a tres divergencias existentes: i) la inclusión o no del concepto intencionalidad en la difusión del contenido falso lo cual excluiría categorías como los errores periodísticos no intencionados; ii) el hecho de excluir el contenido satírico por su natural enfoque hacia el entretenimiento; y iii) la complejidad para incluir ciertos contenidos en la escala de falsedad dado que, por ejemplo, se pueden presentar contenidos con ciertas preferencias o intereses pero que no pueden ser catalogados totalmente como falsos.

Mucho antes del boom de las noticias falsas, Giovanni Sartori (1998) definió la desinformación como "una distorsión de la información: dar noticias falseadas que inducen a engaño al que las escucha" (p. 80). Sartori (1998) pone como ejemplos de desinformación las simplificaciones estadísticas, las entrevistas casuales, los seudoacontecimientos o las exageraciones. Actualmente, ha emergido la intención deliberada de fabricar información para engañar o con la distorsión clara de infringir un daño a través de la manipulación de vídeos, imágenes u otros formatos multimedia. Wardle y Derakhshan (2017) mencionan expresamente los factores de intencionalidad y daño que espolean la propagación de la desinformación para construir un modelo que distingue tres tipologías de desorden informativo: i) misinformation, como el contenido inexacto (estadísticas, atribuciones, entre otras) difundido sin intencionalidad o la sátira cuando se toma en serio; ii) disinformation, como el contenido fabricado o deliberadamente manipulado con la intención de engañar; y iii) malinformation, que referencia la publicación de información basada en lo real para herir a personas, colectivos u organizaciones, por ejemplo, los discursos de odio.

\section{El periodismo de verificación}

En términos prácticos, podríamos definir el periodismo como el oficio de contar lo que pasa (Gabilondo, 2011). Actualmente ocurre, desde una perspectiva informativa, un auge desmesurado de información (datos, declaraciones, imágenes, vídeos, etc.) que circula en la autovía de los medios sociales y de los medios de comunicación tradicionales. El periodismo, cumpliendo su esencia de reportar lo que sucede a nuestro alrededor, se ha adaptado a este nuevo contexto (des)informativo. En este sentido, se ha generado y conformado una nueva práctica periodística denominada periodismo de verificación (fact-checking journalism) de datos, hechos y discursos públicos (Cheruiyot y Ferrer-Conill, 2018; Graves, 2017; Mena, 2019). El incremento 
de este quehacer se ha producido a nivel internacional, tal y como se aprecia en la figura 2. La investigación muestra que el ecosistema de los medios de verificación, si bien se trata de una iniciativa aún en madurez, se construye con base en un patrón compartido por la lógica del isomorfismo institucional que, junto con una creciente vinculación con el sistema institucionalizado de medios tradicionales, contribuye a dotar de legitimidad esta nueva práctica periodística (Lowrey, 2017).

Esta práctica periodística guarda muchas similitudes con la labor tradicional de los medios de comunicación para velar por la exactitud de la información a divulgar. Por ello, la verificación se configura como una nueva-vieja modalidad de hacer periodismo (Palau-Sampio, 2018) con un estilo renovador frente al deterioro de las prácticas periodísticas (Amazeen, 2019). Con ello, se pretende combatir la desinformación, la cual procede con cierta asiduidad de los medios sociales desde donde se viraliza. Esto quiere decir que el verificador se encarga de evaluar la exactitud de los contenidos relevantes por su incidencia social, su relevancia temática o la repercusión de su autor/a. Mientras que el verificador tradicional se asegura de que el reportero incorporó la cita, hechos o datos de forma correcta y exacta; el verificador de noticias falsas evalúa, después de que acontezca el hecho o suceso, si la declaración, dato o contenido es exacto o no para emitir una evaluación basada en un proceso de análisis metodológico (Graves y Glaisyer, 2012).

El proceso de selección y producción periodística de una verificación exige el cumplimiento de unos protocolos procedimentales que habiliten los estándares epistemológicos de imparcialidad, apartidismo y neutralidad. Para ello, tanto la transparencia en la selección del contenido a verificar como el proceso metodológico se convierten en vectores que conducen a que los medios de verificación obtengan confianza ciudadana y credibilidad social (Humprecht, 2019). En un terreno en el que los medios sociales son, cada vez con mayor frecuencia, fuentes de (des)información, el periodismo de verificación se convierte en una nueva práctica de cobertura informativa para combatir las percepciones erróneas, especialmente focalizada en los asuntos públicos y políticos (Lewandowsky, Ecker y Cook, 2017; Magallón-Rosa, 2019; Nyhan y Reifler, 2014; Nyhan et al., 2019; Tuñón-Navarro, Oleart y García, 2019; Wintersieck, 2017).

Para los periodistas que se dedican a la verificación, el propósito principal es evaluar la exactitud de las declaraciones de carácter político (Mena, 2019). Consecuentemente, se erigen como jueces de la verdad ante los ojos de la opinión pública al calificar los contenidos como verdaderos, engañosos o falsos. Por otro lado, este propósito principal induce a pensar que esta práctica aspira a corregir las percepciones erróneas de los ciudadanos, lo que repercute positivamente en 
la mejora de la calidad del debate informado, la calidad de la democracia y en el comportamiento político. No obstante, la evidencia académica más reciente indica que, si bien los efectos existen y son positivos, son limitados sobre todo porque las verificaciones versan sobre asuntos ideológicos (Nyhan et al., 2019; Walter et al., 2019) más difíciles de cambiar debido a las creencias, concepciones y marcos cognitivos previos (figura 2).

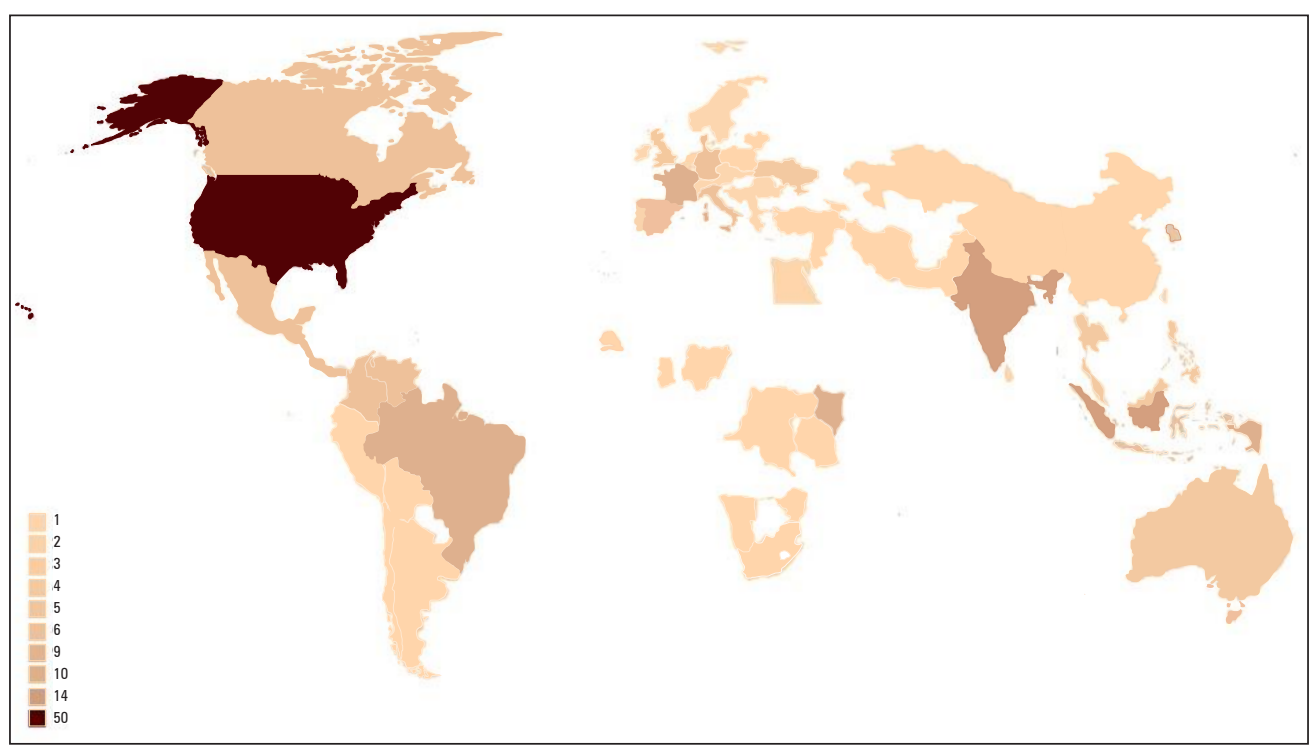

Figura 2. Mapa mundial con los medios de verificación.

Fuente: elaboración propia a partir de Duke Reporters' Lab (2019).

Específicamente en Colombia se identifican tres medios que realizan con asiduidad periodismo de verificación. Colombiacheck y La Silla Vacía son iniciativas periodísticas fundadas recientemente (en 2016 y 2014, respectivamente) con un ámbito de actuación nacional. Colombiacheck (https://colombiacheck.com/) se dedica específicamente al periodismo de verificación, mientras que La Silla Vacía cuenta con una sección concreta, llamada "Detector de mentiras" (https:/lasillavacia.com/ detector-mentiras), donde publica sus verificaciones. Por su parte, la agencia de noticias francesa AFP (Agence France-Presse) desarrolla una nueva línea informativa vinculada con el periodismo de verificación denominada "AFP Factual" (https:// factual.afp.com/list) con contribuciones periodísticas de ámbito internacional en donde también participan sus colaboradores colombianos. Siguiendo la clasificación proporcionada por Graves y Cherubini (2016), Colombiacheck y La Silla Vacía se integran dentro del modelo alternativo, y AFP hace parte del modelo tradicional de los grandes medios de comunicación (tabla 1). 
Tabla 1. Resumen comparado entre los medios analizados

\begin{tabular}{lccccc}
\hline $\begin{array}{c}\text { Medio de } \\
\text { verificación }\end{array}$ & $\begin{array}{c}\text { Ámbito de } \\
\text { cobertura }\end{array}$ & Difusión & $\begin{array}{c}\text { Modelo } \\
\text { organizativo }\end{array}$ & Realización & $\begin{array}{c}\text { Categorías de } \\
\text { verificación }\end{array}$ \\
\hline Colombiacheck & Nacional & En línea & Alternativo & Periodistas & Sí \\
\hline La Silla Vacía & Nacional & En línea & Alternativo & Periodistas & Sí \\
\hline AFP & Internacional & En línea & Tradicional & Periodistas & Sí \\
\hline
\end{tabular}

Fuente: elaboración propia.

\section{Metodología}

El diseño metodológico seguido para el caso de estudio fue mixto y basado en la técnica del análisis de contenido, ampliamente usada en los estudios sobre la comunicación y el mensaje periodístico. Este método mixto permite complementar el enfoque cuantitativo con el cualitativo. La triangulación o concurrencia de los datos (Creswell, 2009) se produce al relacionar el análisis cuantitativo de los actores sociales protagonistas afectados por la desinformación con los argumentos identificados y su incidencia sobre los intangibles (análisis de contenido etnográfico). En primer lugar, se realizó un análisis de contenido cuantitativo, como técnica "objetiva y sistemática" (Berelson, 1966, p. 263), para analizar los datos, obtener frecuencias de aparición y establecer comparaciones entre el contenido manifiesto analizado. En segundo lugar, se recurrió al análisis de contenido etnográfico (Altheide, 1987) para realizar un análisis reflexivo sobre el contenido manifiesto e interpretar las relaciones entre los mensajes.

El primer paso consistió en establecer las pautas para acotar las noticias de verificación susceptibles de ser examinadas. La muestra de análisis se conformó a partir de las verificaciones publicadas por los tres medios de verificación presentes en Colombia, firmantes del Código de Principios del International Fact-Checking Network (Duke Reporters' Lab, 2019) y catalogados en la lista internacional del Duke Reporters' Lab (2019) de la Universidad de Duke. Estos medios son Colombiacheck, La Silla Vacía y AFP Factual Colombia. Por unidad de análisis se identificó toda noticia de verificación con relación directa con el paro nacional con una (verdadero, falso, engañoso) o varias categorías de calificación de la verificación (chequeos múltiples). En total, se contabilizaron noventa y dos unidades de análisis, lo cual configuró la muestra, obtenida desde las páginas web de los medios seleccionados, ya que es posible recopilar las verificaciones asociadas al objeto de estudio. Todas las unidades de análisis se publicaron entre noviembre y diciembre del 2019. 
Para la sistematización del análisis cuantitativo de contenido se implementó un libro de códigos en el que se establecieron las categorías de análisis (calificación del contenido, el formato y el actor social afectado) y los criterios específicos del análisis. Las tres categorías se definieron como categorías nominales. La calificación del contenido se categorizó entre exacto (contenido verdadero), inexacto (categorías como verdadero, pero, cuestionable, engañoso o falso) o no se sabe (inchequeable). El formato de contenido se codificó escogiendo entre estas seis variables: declaraciones reales, imágenes/fotografías, videos, publicación textual, información publicada por medios de comunicación y audios. Los actores afectados se conformaron en cinco grupos: actor político, actor social, actor institucional, otros actores y no se sabe/no se identifica con claridad.

Luego del entrenamiento de los codificadores y con el propósito de asegurar la viabilidad y confiabilidad del instrumento, se realizó un pretest con el fin de hallar el grado de acuerdo entre los dos codificadores (el investigador principal y la coautora). El pretest sobre quince unidades de análisis (16,3 \% de la muestra) elegidas al azar se realizó por los dos codificadores de forma individual e independiente.

A este pretest se le aplicaron los coeficientes kappa de Cohen y el alfa de Krippendorff. Ambos índices son ampliamente usados en la técnica del análisis cuantitativo de contenido y miden los efectos del azar penalizándolos. El valor de la kappa de Cohen mide la concordancia entre dos evaluadores. Valores de $k>0,81$ reflejan una fiabilidad casi perfecta; $0,61<k>0,80$ equivalen a concordancias sustanciales; $0,41<k>0,60$ estipulan acuerdos moderados y niveles de $k$ inferiores indican fiabilidades insuficientes. El valor del alfa de Krippendorff fija que si $\alpha$ es $>0,8$ se ha obtenido una buena fiabilidad intercodificador; si 0,667 $\langle\alpha\rangle$ 0,8 , los resultados se consideran aptos para conclusiones tentativas; mientras que $\alpha$ inferiores se consideran no apropiados. Para hallar ambos coeficientes se recurrió al software estadístico RStudio. Lo resultados mostrados en la tabla 2 otorgan validez y fiabilidad entre los dos codificadores.

Tabla 2. Fiabilidad intercodificador

\begin{tabular}{lcccc}
\hline \multicolumn{1}{c}{ Variable } & $\begin{array}{c}\text { Porcentaje de } \\
\text { acuerdo }\end{array}$ & $\begin{array}{c}\text { Tipo de } \\
\text { variable }\end{array}$ & $\begin{array}{c}\text { Alfa de } \\
\text { Krippendorff }\end{array}$ & $\begin{array}{c}\text { Kappa de } \\
\text { Cohen }\end{array}$ \\
\hline (In)exactitud en la verificación & $100 \%$ & Nominal & 1 & 1 \\
\hline Formato del contenido verificado & $86,7 \%$ & Nominal & 0,82 & 0,815 \\
\hline $\begin{array}{l}\text { Actor (social, político o institucional) afec- } \\
\text { tado por la desinformación }\end{array}$ & $86,7 \%$ & Nominal & 0,762 & 0,756 \\
\hline
\end{tabular}

Fuente: elaboración propia. 
Posteriormente, se codificó la muestra total $(n=92)$. La muestra se compuso en un $65,2 \%(n=60)$ de chequeos publicados por Colombiacheck, La Silla Vacía en un $25 \%(n=23)$ y un 9,78 \% $(n=9)$ de AFP Colombia. Asimismo, el $86,9 \%$ $(n=80)$ de la muestra fue catalogado por los verificadores como inexacto en un grado parcial o total, mientras que el $13,1 \%$ fue calificado como exacto (verdadero).

Una vez realizado el análisis cuantitativo, se procedió con el análisis de contenido etnográfico (Altheide, 1987) sobre ochenta unidades de análisis reportadas como inexactas. Mientras que el análisis de contenido cuantitativo permitió medir la frecuencia de aparición de los actores afectados, el análisis etnográfico del contenido permitió identificar patrones de relación, agrupar conceptos explícitos en el contenido mediático de la muestra y relacionar los argumentos e implicaciones de la desinformación en los actores políticos, sociales e institucionales identificados en el análisis cuantitativo. A partir de estos patrones y conceptos de asociación, es posible identificar y extraer los argumentos y las consecuencias de la desinformación sobre los bienes intangibles de legitimidad, reputación y confianza.

\section{Resultados}

El primer objetivo de investigación se centra en el análisis de los argumentos de los contenidos desinformantes en función de los actores políticos, sociales o instituciones públicas para, así, responder la primera pregunta de investigación. Del conjunto de unidades reportadas como inexactas ( $n=80$ ), el 38,75\% de la desinformación afectó a los actores institucionales, el 28,75\% a los actores sociales, el 17,50 \% a actores políticos, el 12,5\% no se pudo identificar con claridad y el 2,50 \% a otros actores. La tabla 3 organiza los principales argumentos de la desinformación y su relación con los actores sociales, políticos e institucionales.

Tabla 3. Relación entre los principales argumentos de desinformación con los actores sociales, políticos e institucionales

\begin{tabular}{|c|c|c|}
\hline $\begin{array}{c}\text { Principal actor } \\
\text { afectado }\end{array}$ & Principales argumentos de desinformación & Porcentaje \\
\hline \multirow{4}{*}{ Actor social } & Asociación de las marchas con la violencia & $60,87 \%$ \\
\hline & $\begin{array}{l}\text { Difusión de información falsa para desacreditar a líderes sociales o a } \\
\text { grupos sociales indígenas }\end{array}$ & $17,39 \%$ \\
\hline & Afirmación de que las marchas van en contra de la población civil & $13,04 \%$ \\
\hline & Otros & $8,70 \%$ \\
\hline
\end{tabular}




\begin{tabular}{|c|c|c|}
\hline $\begin{array}{l}\text { Principal actor } \\
\text { afectado }\end{array}$ & Principales argumentos de desinformación & Porcentaje \\
\hline \multirow{3}{*}{$\begin{array}{l}\text { Actor } \\
\text { político }\end{array}$} & $\begin{array}{l}\text { Información falsa sobre el posicionamiento de líderes políticos respecto } \\
\text { del paro }\end{array}$ & $71,43 \%$ \\
\hline & Apropiación política de la protesta & $21,43 \%$ \\
\hline & Otros & $7,14 \%$ \\
\hline \multirow{5}{*}{$\begin{array}{l}\text { Actor } \\
\text { institucional }\end{array}$} & $\begin{array}{l}\text { Asociación del Esmad con hechos violentos y abusos contra los } \\
\text { ciudadanos }\end{array}$ & $38,71 \%$ \\
\hline & $\begin{array}{l}\text { Vinculación de la policía con actos vandálicos, daños del patrimonio } \\
\text { urbano y consumo de drogas }\end{array}$ & $19,35 \%$ \\
\hline & Suplantación de identidad de la policía & $19,35 \%$ \\
\hline & Actos de la policía como infiltrados en las protestas & $9,68 \%$ \\
\hline & Otros & $12,90 \%$ \\
\hline
\end{tabular}

Fuente: elaboración propia.

La desinformación que afectó a los actores sociales emitió argumentos que asociaban la movilización social con la violencia, la criminalidad y el vandalismo, esto es, acciones fuera de la ley. Este tipo de argumentos supuso el 60,87 \% de la desinformación que afectó a los actores sociales (por ejemplo: "El paro no dejó ningún policía muerto ni en Facatativá ni en el país"). El segundo argumento más frecuente, con un 17,39 \%, fue la difusión de desinformación que expresamente mencionaba a líderes sociales, colectivos o grupos indígenas (por ejemplo: "No, indígenas del Cauca no están armados con tatucos"). En tercer lugar, el 13,04 \% de los contenidos hallados afirmaban con información inexacta que la manifestación contravenía el bien común de los ciudadanos (por ejemplo: "Imágenes difundidas por Lafaurie no son de 'ritual satánico' sino de performance").

En lo relativo a los actores políticos, predominaron los contenidos que difundían información inexacta sobre el posicionamiento de los principales líderes políticos respecto de la movilización social (71,43 \%), por ejemplo: "No, Petro no ha propuesto a manifestantes tomarse las terminales aéreas del país". Asimismo, afloraron argumentos que divulgaban la apropiación política del paro (21,43\%), por ejemplo: "El Espectador no publicó que Petro 'habría contratado más de 34.000 buses para movilizar protestantes'".

En tercer lugar, entre los actores institucionales afectados por los contenidos verificados como inexactos prevalecen las fuerzas de orden público del Estado, es decir, el Esmad (Escuadrón Móvil Antidisturbios) y la policía. Se observa que 
el nodo principal se encuadra en vincular al Esmad con la violencia y el abuso de poder contra los manifestantes (38,71 \%) (por ejemplo: "Video del Esmad torturando a un hombre no es del paro"). La desinformación ligada a la policía presentó argumentos centrados en el comportamiento para asociarlo con vandalismo (19,35\%) (por ejemplo: "Video de policías drogándose no es de Colombia sino de Chile"; o con informaciones que suplantaban la identidad de la policía para desinformar (19,35 \%) (por ejemplo: "Supuesta cadena de la policía alertando sobre el paro del jueves es falsa").

El análisis de los argumentos asociados a los actores sociales, políticos e institucionales nos permitió responder la primera pregunta de investigación. Se corrobora la primera hipótesis de investigación que afirma que la desinformación influye de forma negativa en bienes intangibles de los actores anteriormente mencionados.

El segundo objetivo específico, relacionado con la segunda pregunta de investigación, plantea relacionar el deterioro en intangibles (legitimidad, reputación y confianza) que ocasiona la desinformación en cada clúster de actores. Los contenidos reportados como inexactos muestran cómo la desinformación lacera el sentimiento de seguridad ciudadana desde una doble vertiente. Por un lado, está la incriminación de la fuerza pública colombiana (policía y Esmad, especialmente) en acciones violentas que sobrepasan los límites del uso legítimo de la fuerza hasta llegar a matar a manifestantes, a protagonizar actos vandálicos y abusos policiales (figura 3). Estos contenidos infringen un daño en la confianza social hacia un cuerpo que actúa, acorde con estos contenidos, conforme a normas y valores sociales no aceptados ni deseados (pérdida de legitimidad) y con una actuación negativa en comparación con el contexto internacional (costes reputacionales). Ello se produjo a través de desinformación que vincula la fuerza pública con la drogadicción, el vandalismo, la tortura o la agresión a los manifestantes, con un fin claro de generar un daño y desacreditar la institución.

Por otro lado, los contenidos evaluados como desinformación, dirigidos hacia los actores sociales, evidencian la asociación de la movilización social con la protesta violenta, lo cual desacredita y deslegitima el paro nacional y suscita un ambiente de alarma y tensión en la reivindicación (figura 4). De esta manera, circularon contenidos para la deslegitimación social en términos individuales — como en el caso de Dilan Cruz, joven que falleció a causa de un disparo del Esmad y quien fue objeto de desinformación donde se afirmaba que participaba en actos vandálicos-, colectivos - por ejemplo, con contenidos donde los grupos indígenas aparecían armados - o a la marcha en sí misma y a sus participantes en el papel de vándalos que destrozan infraestructuras públicas, patrimonio privado y que agreden, ocasionando la muerte, a la fuerza pública. 


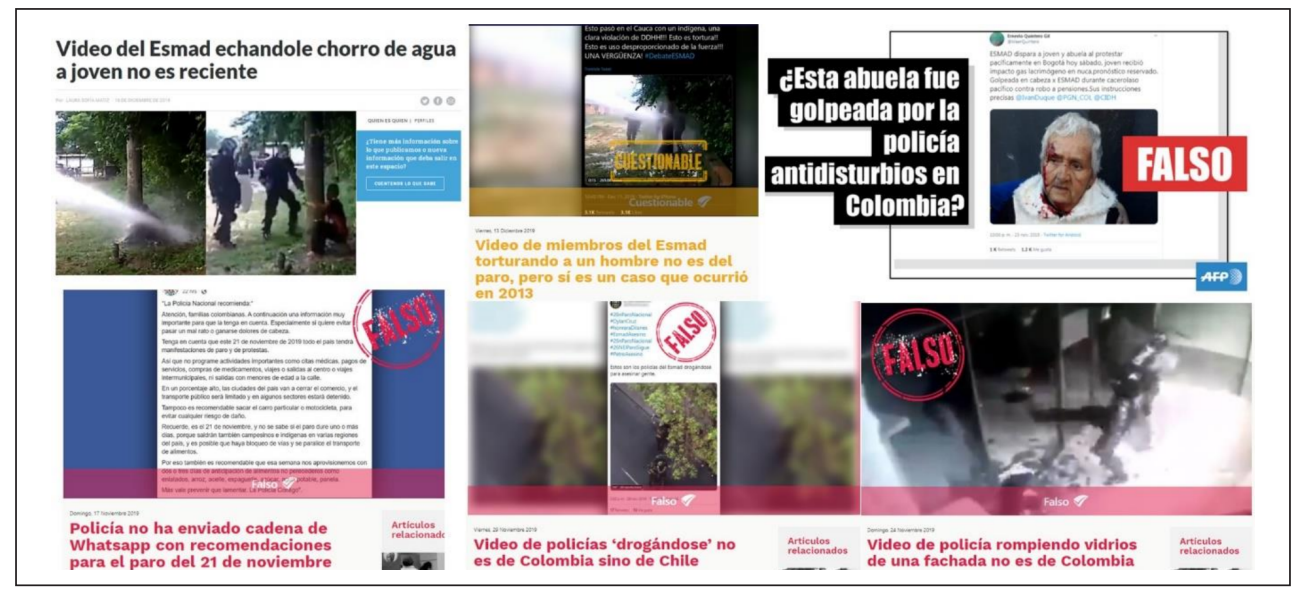

Figura 3. Ejemplo de desinformación asociada a actores institucionales Fuente: capturas de pantalla de Saavedra (2019), Matiz (2019c) y AFP (2019).

Por otro lado, los contenidos evaluados como desinformación, dirigidos hacia los actores sociales, evidencian la asociación de la movilización social con la protesta violenta, lo cual desacredita y deslegitima el paro nacional y suscita un ambiente de alarma y tensión en la reivindicación (figura 4). De esta manera, circularon contenidos para la deslegitimación social en términos individuales - como en el caso de Dilan Cruz, joven que falleció a causa de un disparo del Esmad y quien fue objeto de desinformación donde se afirmaba que participaba en actos vandálicos-, colectivos - por ejemplo, con contenidos donde los grupos indígenas aparecían armados - o a la marcha en sí misma y a sus participantes en el papel de vándalos que destrozan infraestructuras públicas, patrimonio privado y que agreden, ocasionando la muerte, a la fuerza pública.

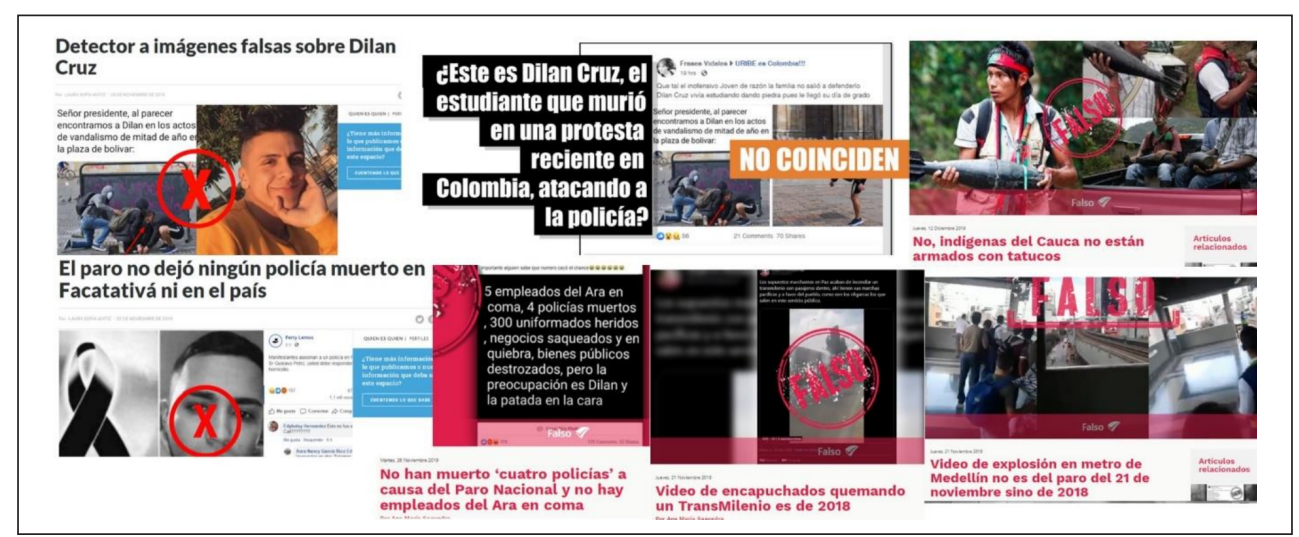

Figura 4. Ejemplos de desinformación asociada a actores sociales Fuente: capturas de pantalla de Saavedra (2019b), Matiz (2019b) y AFP (2019a). 
Estos argumentos desinformantes crean dinámicas que inducen a la polarización social y, por tanto, hacia la deslegitimación, por un lado, de las instituciones que forman las fuerzas y cuerpos de seguridad del Estado; y, por otro lado, hacia la deslegitimación del derecho del pueblo a ejercer la manifestación pública y pacífica.

Focalizado en los actores políticos, la desinformación verificada tuvo en Gustavo Petro, líder político del partido Colombia Humana, senador y rival del presidente Iván Duque durante las elecciones presidenciales del 2018, al principal damnificado. Estos hechos alternativos afectaron tanto al presidente Duque como al alcalde de Medellín —o al propio Gustavo Petro — con el consiguiente objetivo de emparejar dichas figuras públicas con atributos y características ficticias. En el caso de Duque fue marchar contra su propio Gobierno; en el caso del alcalde de Medellín, sugerir su vinculación con encapuchados violentos; en el caso del senador Petro, se afirmó la promoción de actos incívicos e, incluso, con el fomento de una revuelta y subversión con la toma de aeropuertos, cuarteles y sedes de la policía (figura 5).

En virtud del análisis de los efectos que dichos argumentos tienen en los diferentes actores (pregunta 2), corroboramos que se cumple la segunda hipótesis de investigación que sostiene que la desinformación se convierte en un riesgo para la legitimidad, reputación y confianza social de los actores sociales, políticos e institucionales.

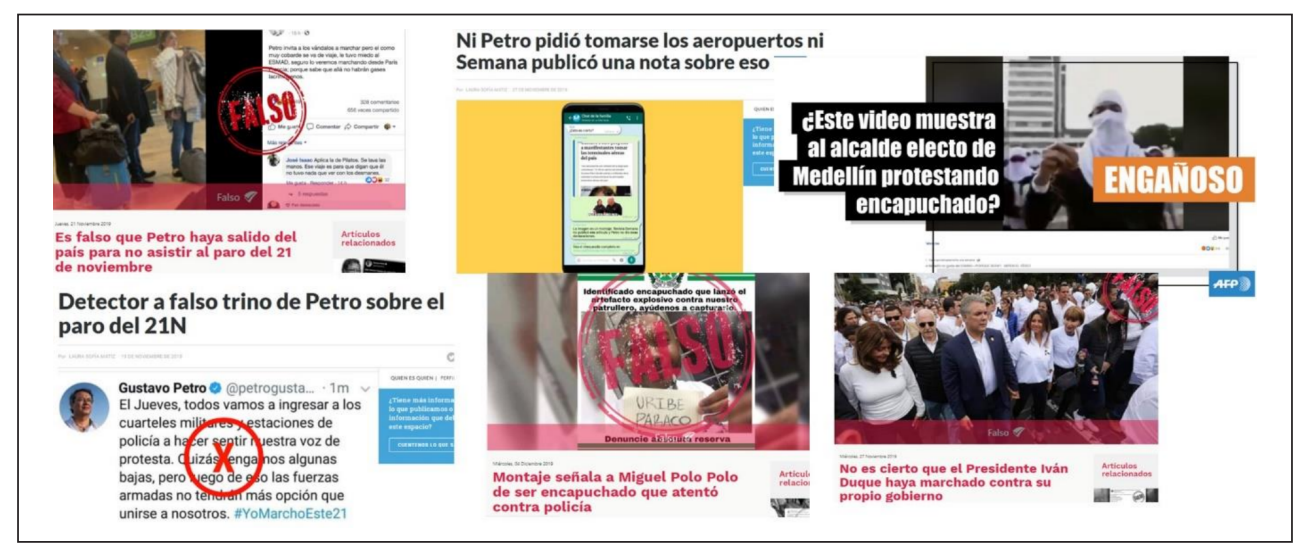

Figura 5. Ejemplos de desinformación asociada a actores políticos

Fuente: captura de pantalla de Saavedra (2019), Matiz (2019a) y AFP (2019b).

Por último, el análisis etnográfico también permitió identificar y reseñar una estrategia empleada por los productores de desinformación que consistió en suplantar la identidad de medios de comunicación (figura 6). En el intento de la desinformación de erigirse con credibilidad social, varios contenidos verificados 
como inexactos recurrieron a las marcas periodísticas como Revista Semana, El Tiempo o El Espectador, entre otros, como instrumentos legitimadores. De esta manera, imitaron su estética y se apropiaron fraudulentamente de la marca y de la identidad corporativa.

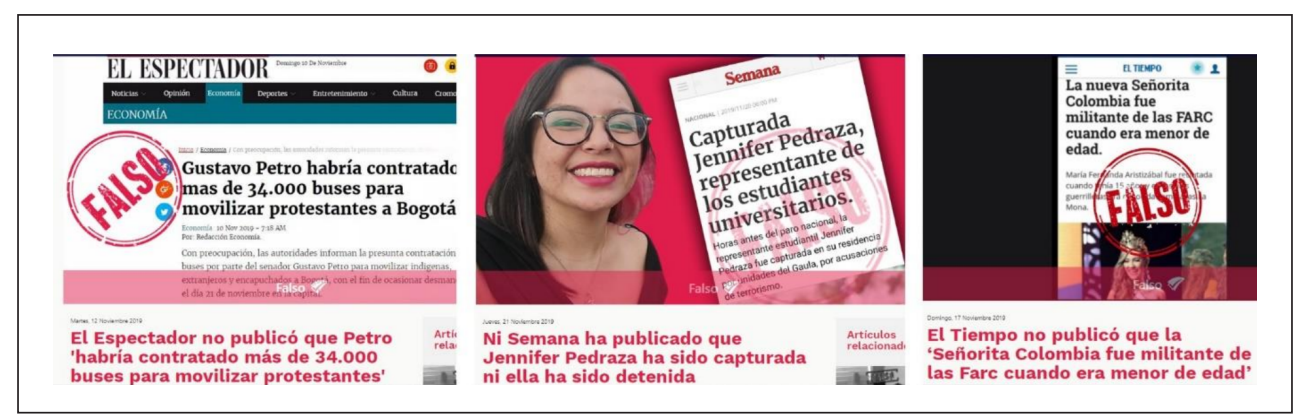

Figura 6. Ejemplos de suplantación de identidad de medios de comunicación Fuente: captura de pantalla de Saavedra (2019a).

\section{Discusión y conclusiones}

Como se desprende del análisis de los resultados, la gran mayoría de los contenidos verificados fueron evaluados como inexactos y, por tanto, como desinformación. Estos contenidos falsos e inexactos adoptaron unos marcos de deslegitimación de los actores institucionales, sociales y políticos. Tanto los actores sociales, encarnados en los manifestantes, como la Fuerza Pública fueron objetos de desinformación bajo un prisma común: la asociación con la violencia y los actos punitivos. Ello propicia la configuración de un clima polarizado entre un ellos y un nosotros; un estado de alarma y tensión que rodeó la movilización social como vector deslegitimador. No obstante, esto no exonera lo que realmente ocurrió y el balance de la protesta social en los trescientos cincuenta municipios en los que tuvo lugar la movilización social, que cubrieron treinta y un de los treinta y dos departamentos del país. El balance produjo tres fallecidos, ciento veintidós heridos, noventa y ocho detenidos y ciento cincuenta y un agentes heridos de la Fuerza Pública (Olaya, 2019). El ministro de defensa comunicó que se abrieron once indagaciones sobre el proceder de la policía (El Espectador, 2019). En Bogotá, el alcalde tasó en veintiún mil millones de pesos colombianos el coste de los daños ocasionados, donde sesenta y ocho estaciones de TransMilenio, el transporte público de la ciudad de Bogotá, sufrieron actos vandálicos (Semana, 2019).

Todo ello viene a presentar que los hechos sobre los que trata la desinformación responden a una lógica anclada en lo real y hace más difícil que el ciudadano pueda identificar lo que ocurrió de verdad de lo que no. Por tanto, se pone de 
manifiesto que la desinformación se nutre del contexto social real para exacerbar acciones y opiniones desde lo emocional a partir de percepciones sobre lo real. La lógica discursiva en la construcción de la opinión pública se asienta sobre los hechos discursivos. Como sostiene Carrera (2018), "los hechos no pertenecen ni a un mundo objetivo ni a un mundo subjetivo, sino al mundo del relato y del discurso" (p. 1473). En estos relatos predominan sentimientos, la emocionalidad y las creencias previas. En este sentido, afirman Morales-Romero y Martínez-Martínez (2020):

La posverdad ha desplazado la clásica manera de entender la realidad y de concebir la verdad. Esta ya no se percibe como algo estable y duradero, sino como una zona de confort donde confluyen creencias y opiniones personales, y en donde las emociones y los sentimientos personales juegan un papel preponderante. (p. 125)

Lo que sucede en la realidad sirve como base y coartada para difundir información similar, pero falsa o fraudulenta (manipulada o que circula fuera del contexto original, por ejemplo), que polariza socialmente, amplía las divergencias sociales y dificulta los consensos.

Del mismo modo, como efecto búmeran, estos contenidos falsos, tan parecidos a los hechos que realmente sí ocurrieron, posibilitan el escepticismo hacia las cifras y los hechos por las similitudes entre los verdadero y lo falso. Informes internacionales como el Digital News Report del Instituto Reuters (Newman et al., 2019) manifiestan la preocupación ciudadana para poder discernir entre lo que es verdad y lo que es mentira. Si bien durante la protesta hubo hechos reales que cuestionan la actuación del Esmad, cabría preguntarse cómo la desinformación alimentó el debate nacional posterior que surgió sobre si había que disolver el Esmad.

En un entorno de desconfianza hacia las instituciones y entes gubernamentales a nivel mundial —y Colombia no es una excepción (Corporación Latinobarómetro, 2018) —, la desinformación contribuye a cultivar entornos polarizados presentando hechos alternativos que percuten negativamente sobre la legitimidad, reputación y confianza de actores e instituciones. Por ello, una de las principales implicaciones estriba en que la desinformación se disfraza de información real siguiendo la agenda y el cubrimiento informativo de los acontecimientos para camuflarse con lo real y distribuirse a través de los medios sociales. Ello posibilita un doble efecto: la polarización social y el aumento del escepticismo social al no saber en qué fuentes y en qué información confiar. Esta perspectiva puede abrir futuras líneas de investigación sobre desinformación y resiliencia social.

El periodismo de verificación, mediante su quehacer, intenta que el coste-beneficio, cuando un actor público relevante propaga desinformación, sea negativo por su daño reputacional (Nyhan y Reifler, 2014). Pero cuando se enfrenta a contenidos 
virales propagados por granjas de bots o perfiles anónimos, dicho propósito se desvanece. Particularmente, en este caso de estudio, mayoritariamente se verificó información multimedia compartida en medios sociales (redes sociales públicas o aplicaciones de mensajería como WhatsApp). Ello suscita una futura línea de investigación para conocer cómo conciben los periodistas verificadores en Colombia y Latinoamérica lo que debe ser la principal función del periodismo de verificación, esto es, conocer qué peso debe tener el escrutinio al discurso público y la verificación de contenidos virales propagados en medios sociales. Ello permitiría observar si hay diferencias con el periodismo de verificación estadounidense donde el propósito principal es la evaluación del discurso de figuras públicas e instituciones (Mena, 2019).

La labor de verificación depende de la identificación y análisis de la procedencia de los datos y de los contenidos multimedia. Este aspecto requiere un trabajo de veeduría y competencias digitales para los futuros periodistas (Ufarte-Ruiz, Peralta-García y Murcia-Verdú, 2018) debido a que los contenidos se viralizan sin su contexto o sin las citas a las fuentes (Mazaira-Castro, Rúas-Araújo y Puentes-Rivera, 2019). Los medios sociales, sus alertas y notificaciones son estímulos del día a día de los periodistas para informar y comunicar, así como permiten la interacción con los públicos al responder sus consultas. Además, son un desafío para incorporar rigurosidad y precisión al tratamiento de la información (Palomo y Sedano, 2018) en el entorno de instantaneidad.

Como evidenciaron Hernández-Cadena et al. (2018), los medios de comunicación que realizan verificaciones tienen que ser capaces de alcanzar las comunidades que divulgan los contenidos falsos o engañosos. Este reto requiere la colaboración con las empresas tecnológicas para que los algoritmos de las redes sociales primen las noticias de verificación y las expongan en las comunidades ideologizadas o partidistas en las que haya una desinformación circulando.

Como resultado del análisis, la desinformación generó relatos para reforzar posicionamientos ideológicos a favor o en contra de la movilización social con la violencia como eje y vector de deslegitimación social, política o institucional. Estos relatos de desinformación se articulan desde las emociones que manifiesta el hecho violento en un contexto en el que los relatos - también los periodísticos-cada vez ostentan una mayor carga emocional (Wahl-Jorgensen, 2012). Futuras líneas de investigación pueden explorar los procesos de cognición y la convivencia y eficacia de la verificación de hechos cuando las creencias y concepciones hacen parte de modos de ver el mundo y marcos mentales asentados en discursos y relatos ya elaborados, sobre todo en los temas políticos con gran carga ideológica que fomentan la polarización. 
Precisamente, los medios de verificación juegan actualmente en los mismos marcos conceptuales que los contenidos falsos o engañosos. En este sentido, caen en la trampa de lo que ya advirtió Lakoff (2007) en su libro No pienses en un elefante. Al recurrir a los mismos conceptos y enmarcados para rebatirlos, se genera un potencial efecto adverso al activar dichos marcos cognitivos de interpretación de la realidad en la mente del usuario y el riesgo de la imprimación (priming) de ciertos atributos que evoca la desinformación. El propio Lakoff (Lakoff, 2018) está divulgando su recomendación sobre cómo combatir la desinformación desde el periodismo de verificación: el primer marco debe ser el de la verdad; en segundo lugar, hay que señalar la mentira sin amplificarla; en tercer lugar, se tiene que repetir la verdad asegurándose de que tenga más presencia que la mentira a rebatir. Este planteamiento concuerda con otras investigaciones (Walter y Tukachinsky, 2020) que destacan la importancia de que la verificación tenga una lógica discursiva propia que evidencie las carencias de la información falsa, argumente la corrección e incluya, cuando se pueda, fuentes que compartan un contexto con la fuente propagadora de la desinformación. Walter y Tukachinsky (2020) indican, como ejemplo, una desinformación sobre autismo a causa de las vacunas: la verificación será más eficaz si incluye como fuentes a familias con menores autistas a favor de las vacunas.

En definitiva, este artículo surgió con el objetivo de analizar los costes que infringe la desinformación en los bienes intangibles de legitimidad, reputación y confianza de los actores sociales, políticos e institucionales como fruto de la polarización social y la creación de narrativas alternativas ficticias o manipuladas para hacerlas circular en otros contextos o modificar su sentido original. El análisis de caso se centró en un momento social convulso como el de un paro nacional del $21 \mathrm{~N}$, ya de por sí proclive a la polarización social. Para ello, se recopilaron las verificaciones realizadas por los tres medios periodísticos que realizan periodismo de verificación en Colombia de forma frecuente cumpliendo los principios éticos y metodológicos establecidos internacionalmente. Por tanto, este análisis se limita a un caso de estudio concreto. Se recomienda que futuras investigaciones profundicen en los efectos que tiene la desinformación sobre los actores políticos, sociales e institucionales en distintos contextos sociales, políticos, económicos o sanitarios. El análisis de dichos argumentos permitirá comparar su relación y afectación en intangibles tales como la legitimidad, la reputación o la confianza a través de tipologías de argumentos o lógicas discursivas de la desinformación.

Se hallaron casi un centenar de verificaciones relacionadas directamente con el paro nacional. Los resultados muestran que la desinformación relacionó a los actores sociales y a los actores institucionales, principalmente a la fuerza pública, con la violencia y los actos punibles como argumento vector de la desinformación. 
Ello permite catalogar estos contenidos dentro de un componente dañino para las instituciones y para la movilización social con una intencionalidad clara por deslegitimar y desprestigiar las actuaciones y procedimientos.

Con respecto a la desinformación que ofrecía hechos alternativos sobre posicionamientos políticos, se observa cierta transversalidad ideológica aunque el líder de la izquierda colombiana adquirió más prominencia como actor afectado por los contenidos inexactos. La desinformación emitió falsos posicionamientos del senador Petro respecto de la protesta y alentó la confrontación social al atribuirle, por ejemplo, afirmaciones para tomar infraestructuras públicas críticas de un Estado.

Por último, es necesario prestar atención a la estrategia de desinformación a partir de legitimarse substrayendo la marca e identidad corporativa de los medios de comunicación reconocidos por su labor informativa. Esto se hace con el fin de aprovecharse de esa confianza de los ciudadanos hacia estos medios, lo que permite que el ruido y la mentira se convierta y transmita como asunción de verdad informativa. La desinformación abre una nueva brecha en donde, como los parásitos, se alimenta del quehacer de los medios periodísticos para difundirse, contaminar la opinión pública y esparcir la mentira.

\section{Referencias}

AFP factual (2019a, 29 de noviembre). Esta mujer fue lesionada en julio de 2019 en Chile, no en las protestas de noviembre en Colombia. AFP FACTUAL. https://factual.afp.com/esta-mujer-fue-lesionadaen-julio-de-2019-en-chile-no-en-las-protestas-de-noviembre-en-colombia

AFP factual (2019b, 11 de diciembre). El video original muestra a Daniel Quintero en una manifestación contra la violencia en Bogotá. AFP FACTUAL. https://factual.afp.com/el-video-original-muestradaniel-quintero-en-una-manifestacion-contra-la-violencia-en-bogota

Allcott, H. y Gentzkow, M. (2017). Social media and fake news in the 2016 election. Journal of Economic Perspectives, 31(2), 211-236. http://doi.org/gc5t4c

Altheide, D. L. (1987). Reflections: Ethnographic content analysis. Qualitative Sociology, 10(1), 6577. http://doi.org/d87526

Amazeen, M. A. (2019). Practitioner perceptions: Critical junctures and the global emergence and challenges of fact-checking. International Communication Gazette, 81(6-8), 541-561. http:// doi.org/gfsjfb

Baym, G. (2005). The Daily Show: Discursive integration and the reinvention of political journalism. Political Communication, 22(3), 259-276. http://doi.org/d93vz6

BBC (2019, 21 de noviembre). Paro nacional en Colombia: por qué la protesta del 21 de noviembre genera tanta tensión. BBC. https://bbc.in/2GHYbql 
Bennett, W. L. y Livingston, S. (2018). The disinformation order: Disruptive communication and the decline of democratic institutions. European Journal of Communication, 33(2), 122-139. https://doi.org/gdfqg6

Berelson, B. (1966). Content Analysis in communication research. En B. Berelson y M. Janowitz (eds.), Reader in public opinion and communication (2a edición) (pp 260-267). The Free Press.

Canel, M. J., y Luoma-aho, V. (2017). ¿Qué aportan los bienes intangibles a la administración pública? En M. J. Canel, P. Piqueiras., y G. Ortega (Eds.), La comunicación de la Administración Pública. Conceptos y casos prácticos de bienes intangibles (pp. 29-50). Instituto Nacional de Administración Pública.

Carrera, P. (2018). Estratagemas de la posverdad. Revista Latina De Comunicación Social, 73, 14691482. https://doi.org/fcnc

Cheruiyot, D. y Ferrer-Conill, R. (2018). Fact-Checking Africa. Digital Journalism, 6(8), 964-975. http://doi.org/gfj4bp

Corporación Latinobarómetro. (2018). Corporación Latinobarómetro 2018. https://bit.ly/2RUX6h8

Creswell, J. W. (2009). Editorial: Mapping the field of mixed methods research. Journal of Mixed Methods Research, 3(2), 95-108. https://doi.org/d2qmxx

DANE (2019). Encuesta de cultura política (ECP). Departamento Administrativo Nacional de Estadística. https://bit.ly/39qnAlo

Duke Reporters' Lab (2019). Global fact-checking sites. Reporters' Lab. https://bit.ly/3leZhZH

Duque-Daza, J. (2020). Las elecciones presidenciales de colombia en 2018: Candidatos, autocandidatos y seudocandidatos. Revista Colombiana De Ciencias Sociales, 11(1), 234-266. https:// doi.org/fcq5

EL Espectador (2019, 22 de noviembre). Tres muertos en Valle y 11 indagaciones por exceso de fuerza policial dejan el paro. https://bit.ly/2JVXFao

European Commission. (2018). Flash Eurobarometer 464. Fake News and Disinformation Online. https:// bit.ly/30YkJtg

Gabilondo, I. (2011). El fin de una época: sobre el oficio de contar las cosas. Barril Barral.

García, J. (2012). Latinoamérica: entre la democracia y el autoritarismo. Estudios Políticos, 41, 15-35.

Graves, L. (2017). Anatomy of a fact check: Objective practice and the contested epistemology of fact checking. Communication, Culture \& Critique, 10(3), 518-537. http://doi.org/gcpv6z

Graves, L. y Cherubini, F. (2016). The Rise of Fact-Checking Sites in Europe. Reuters Institute for the Study of Journalism. https://reutersinstitute.politics.ox.ac.uk/sites/default/files/research/ files/The\%2520Rise\%2520of\%2520Fact-Checking\%2520Sites\%2520in\%2520Europe.pdf

Graves, L. y Glaisyer, T. (2012). The fact-checking universe in Spring 2012. New America Foundation, 22. https://bit.ly/2GsYmT5

Hagan, H. (2019). ¿Quiénes confían en los medios de comunicación en las Américas? Barómetro de las Américas. Perspectivas, (142). https://bit.ly/2uZR3jr 
Hernández-Cadena, F., Morales, Á L., Camiña, P., Vargas-Pulido, J. D. y Espeleta, C. (2018). Impacto de las redes sociales en el proceso electoral colombiano. En Misión de Observación Electoral (ed.). Medios de comunicación, redes sociales y democracia. Elecciones presidenciales y legislativas 2018 (pp. 17-38). Misión de Observación Electoral.

Humprecht, E. (2019). How Do They Debunk "Fake News" A Cross-National Comparison of Transparency in Fact Checks. Digital Journalism. http://doi.org/dknc

Huntington, S. (1994). La tercera ola. La democratización a finales del siglo XX. Paidós.

Invamer Gallup (2019) Opinión pública sobre gobernantes, personajes, instituciones y hechos de actualidad. https://bit.ly/30Uraho

Lakoff, G. (2007). No pienses en un elefante: lenguaje y debate político. Editorial Complutense.

Lakoff, G. (Anfitrion). (2018). Truth Sandwich Time. [Podcast]. Soundcloud. https://soundcloud.com/ user-253479697/14-truth-sandwich-time

Lewandowsky, S., Ecker, U. K. y Cook, J. (2017). Beyond misinformation: Understanding and coping with the "post-truth" era. Journal of Applied Research in Memory and Cognition, 6(4), 353-369. http://doi.org/gf3gx4

Lowrey, W. (2017). The Emergence and Development of News Factchecking Sites. Journalism Studies, 18(3), 376-394. http://doi.org/dknd

Magallón-Rosa, R. (2019). Verificado México 2018: Desinformación y fact-checking en campaña electoral. Revista De Comunicación, 18(1), 234-258. http://doi.org/dkng

Matiz, L. (2019a, 19 de noviembre). Detector a falso trino de Petro sobre el paro del 21N. La silla vacía. https://lasillavacia.com/detector-falso-trino-petro-sobre-paro-del-21n-74577

Matiz, L. (2019b, 29 de noviembre). Detector a imágenes falsas sobre Dilan Cruz. La silla vacía. https:// lasillavacia.com/detector-imagenes-falsas-sobre-dilan-cruz-74765

Matiz, L. (2019c, 16 de diciembre). Video del Esmad echandole chorro de agua a joven no es reciente. La silla vacía. https://lasillavacia.com/video-del-esmad-echandole-chorro-agua-joven-no-reciente-74985

Mazaira-Castro, A., Rúas-Araújo, J. y Puentes-Rivera, I. (2019). Fact-checking en los debates electorales televisados de las elecciones generales de 2015 y 2016. Revista Latina De Comunicación Social, (74), 748 766. https://doi.org/fcgw

Mena, P. (2019). Principles and boundaries of fact-checking: Journalists' perceptions. Journalism Practice, 13(6), 657-672. http://doi.org/ggd497

Molina, M. D., Sundar, S. S., Le, T. y Lee, D. (2019). "Fake News" Is Not Simply False Information: A Concept Explication and Taxonomy of Online Content. American Behavioral Scientist, 1-33. http://doi.org/dknh

Morales-Romero, F. B. y Martínez-Martínez, R. R. (2020). La posverdad: Identidades colectivas que degeneran las democracias. Anagramas Rumbos y Sentidos de la Comunicación, 19(37), 111-126. https://doi.org/10.22395/angr.v19n37a6

Moreno, A., Molleda, J. C., Álvarez Nobell, A., Herrera, M., Athaydes, A. y Suárez, A. M. (2019). Comunicación estratégica y sus retos: fake news, confianza, información para la toma de decisiones, 
liderazgo y compromiso laboral. Resultados de una encuesta en 19 países. Euprera; Dircom. https:// bit.ly/2voWDfj

Newman, N., Fletcher, R., Kalogeropoulos, A. y Kleis Nielsen, R. (2019). Digital News Report 2019. Reuters Institute. https://bit.ly/2RzezNe

Nyhan, B., E Reifler, J. (2014). The Effect of Fact-Checking on Elites: A Field Experiment on U.S. State Legislators. American Journal of Political Science, 59(3), 628-640. http://doi.org/f7jq83

Nyhan, B., Porter, E., Reifler, J., E Wood, T. J. (2019). Taking fact-checks literally but not seriously? The effects of journalistic fact-checking on factual beliefs and candidate favorability. Political Behavior, 1-22. http://doi.org/gfzdvm

OCDE. (2018). A Broken Social Elevator? How to Promote Social Mobility. https://bit.ly/37zQsn1

Olaya, M. (2019, 22 de noviembre). Los números de las protestas: tres muertos, 120 lesionados y 98 detenidos. Rcnradio.com. https://bit.ly/3oP5LAx.

Organización de los Estados Americanos, OEA (2017). Declaración conjunta sobre libertad de expresión y "noticias falsas" ("fake news"), desinformación y propaganda. https://bit.ly/38Inx05 .

Ortiz, M. P. (2019, 30 de noviembre). 'Es una manifestación de los jóvenes, unidos por el desencanto' Estas marchas han sido diferentes en muchos aspectos. El historiador Jorge Orlando Melo los analiza. El Tiempo. https://bit.ly/36qFsqy

Palau-Sampio, D. (2018). Fact-checking y vigilancia del poder: la verificación del discurso público en los nuevos medios de América Latina. Comunicación y Sociedad, 31(3), 347-365. doi: 10.15581/003.31.3.347-365

Palomo, M. B. y Sedano, J. (2018). WhatsApp como herramienta de verificación de fake news. el caso de B de bulo. Revista Latina De Comunicación Social, (73), 1384 1397. https://doi.org/fcgx.

Revista Semana (2019, 20 de noviembre). Qué es el Foro de Sao Paulo, al que vinculan con las protestas en Chile o Colombia. Semana. https://bit.ly/36wtkYV

Rodríguez-Pérez, C. (2019). No diga fake news, di desinformación: una revisión sobre el fenómeno de las noticias falsas y sus implicaciones. Comunicación, 40, 65-74. http://doi.org/dkm7

Saavedra, A. (2019a, 12 de noviembre). El Espectador no publicó que Petro 'habría contratado más de 34.000 buses para movilizar protestantes'. https://colombiacheck.com/chequeos/el-espectadorno-publico-que-petro-habria-contratado-mas-de-34000-buses-para-movilizar

Saavedra, A. (2019b, 13 de Diciembre). Video de miembros del Esmad torturando a un hombre no es del paro, pero sí es un caso que ocurrió en 2013. Colombiacheck. https://colombiacheck.com/ chequeos/video-de-miembros-del-esmad-torturando-un-hombre-no-es-del-paro-perosi-es-un-caso-que

Sartori, G. (1998). Homo videns: la sociedad teledirigida. Taurus.

Schmitt, C. (2014). El concepto de lo político. Editorial Alianza

Semana (2019, 22 de noviembre). Habrá ley seca en Bogotá desde el mediodía: Peñalosa. https://bit. ly/37XRMS8. 
Strömbäck, J. (2008). Four Phases of Mediatization: An Analysis of the Mediatization of Politics. The International Journal of Press/Politics, 13(3), 228-246. http://doi.org/chvcmh

Tandoc, E. C., Lim, Z. W. y Ling, R. (2018). Defining "fake news". A typology of scholarly definitions Digital Journalism, 6(2), 137-153. http://doi.org/gdgzp5

Tenove, C. (2020). Protecting democracy from disinformation: Normative threats and policy responses. The International Journal of Press/Politics, 25(3), 517-537. https://doi.org/fcnj

Tuñón-Navarro, J., Oleart, Á y García, L. B. (2019). Actores Europeos y Desinformación: la disputa entre el factchecking, las agendas alternativas y la geopolítica. Revista de Comunicación, (18), 245-260. http://doi.org/dkm8

Ufarte-Ruiz, M., Peralta-García, L. y Murcia-Verdú, F. (2018). Fact checking: Un nuevo desafío del periodismo. El Profesional De La Información, 27(4), 733-741. https://doi.org/fcgv

Vargo, C. J., Guo, L. y Amazeen, M. A. (2018). The agenda-setting power of fake news: A big data analysis of the online media landscape from 2014 to 2016. New Media E Society, 20(5), 20282049. http://doi.org/gc92vf

Wahl-Jorgensen, K. (2012). The strategic ritual of emotionality: A case study of Pulitzer Prizewinning articles. Journalism: Theory, Practice \& Criticism, 14(1), 129-145. http://doi.org/dkm9

Walter, N., Cohen, J., Holbert, R. L. y Morag, Y. (2019). Fact-Checking: A Meta-Analysis of What Works and for Whom. Political Communication, 1-26. http://doi.org/dknb

Walter, N. y Tukachinsky, R. (2020). A meta-analytic examination of the continued influence of misinformation in the face of correction: How powerful is it, why does it happen, and how to stop it? Communication Research, 47(2), 155-177. https://doi.org/gf49vj

Wardle, C. y Derakhshan, H. (2017). Information Disorder: Toward an interdisciplinary framework for research and policymaking. Council of Europe Report. https://bit.ly/315HrOi

Weeks, B. E. y Gil de Zúñiga, H. (2019). What's Next? Six Observations for the Future of Political Misinformation Research. American Behavioral Scientist, 1-13. http://doi.org/gf9nw8

Wintersieck, A. L. (2017). Debating the Truth: The Impact of Fact-Checking During Electoral Debates. American Politics Research, 45(2), 304-331. http://doi.org/f9w8hc

Yaffe, L. (2011). Conflicto armado en colombia: Análisis de las causas económicas, sociales e institucionales de la oposición violenta. Revista CS, (8), 187-208. https://doi.org/fcnm

Zechmeister, E. J. y Lupu, N. (2019). El Barómetro de las Américas 2018/19. Actualidad, (36). https:// bit.ly/38KUBEL

Zimmermann, F. y Kohring, M. (2020). Mistrust, Disinforming News, and Vote Choice: A Panel Survey on the Origins and Consequences of Believing Disinformation in the 2017 German Parliamentary Election. Political Communication, 1-23. http://doi.org/ggh6ft 